\title{
BIODIESEL PRODUCTION FROM MICROWAVE IRRADIATED REACTOR USING HOMOGENEOUS AND HETEROGENEOUS CATALYSIS
}

\author{
S. N. Rabelo, \\ L. S. Oliveira, \\ and A. S. França \\ Universidade Federal de Minas Gerais \\ Departamento de Engenharia Mecânica \\ Bairro Pampulha \\ CEP. 31270-901 \\ Belo Horizonte, Minas Gerais, Brasil \\ sasanogueirarab@hotmail.com \\ Received: April 14, 2018 \\ Revised: May 11, 2018 \\ Accepted: May 28, 2018
}

ABSTRACT

Biodiesel was successful produced in a microwave irradiation reactor using homogeneous and heterogeneous catalysis. The biodiesel was production by the trasesterification reaction of soybean oil using metanol. Sodium methylate ( $30 \%$ solution in metanol) was used for the homogeneous catalyst and the heterogeneous catalyst was developed using wasted eggshells. The eggshells were calcined and tested pure and doped with potassium hydroxide in 10,30 and $50 \%$ of weight. The power and temperature of the microwave were kept constant in every reaction being $800 \mathrm{~W}$ and $200^{\circ}$ Celsius, respectively. The reaction time was significantly reduced using microwave compared to the conventional process. In only one minute of reaction, the methyl ester (FAME) conversion obtained was $98.9 \%$ with the homogeneous catalyst and within 15 minutes, the heterogeneous catalysis accomplished $100 \%$. For heterogeneous catalyst, the best results were acquired when the doped catalyst contained $50 \%$ of $\mathrm{KOH}$. The results indicated that the eggshells treated with $\mathrm{KOH}$ has a great potential to be used for microwave-assisted transesterification reactions of oils with mild operations conditions: molar ratio oil/alcochol $1: 6$ and just $5 \%$ of catalyst. In addition, the heterogenous catalyst was recovered and reused in other reactions with a relatively satisfying results. The physico-chemical properties of the catalysts were characterized by X-ray diffraction and thermogravimectric analysis.

Keywords: biodiesel, homogeneous catalysis, heterogeneous catalysis, microwave reactor, wasted eggshells

\section{NOMENCLATURE}

$\begin{array}{ll}\mathrm{CaO} & \text { calcium oxide } \\ \mathrm{CaCO}_{3} & \text { calcium carbonate } \\ \mathrm{CaO} . \mathrm{H}_{2} \mathrm{O} & \text { hydrated calcium oxide } \\ \text { FAME } & \text { fatty acid methyl esters } \\ \mathrm{KOH} & \text { potassium hydroxide } \\ \mathrm{K}_{2} \mathrm{Ca}\left(\mathrm{CO}_{3}\right)_{2} & \text { calcium and potassium carbonate } \\ \mathrm{NaOH} & \text { sodium hydroxide } \\ \mathrm{NaOCH} & \text { sodium methylate } \\ \mathrm{m} & \text { meter } \\ \mathrm{min} & \text { minutes } \\ \mathrm{mL} & \text { milliliter } \\ \mathrm{mm} & \text { millimeter } \\ \mathrm{rpm} & \text { revolutions per minute } \\ \mathrm{SrO} & \text { strontium oxide } \\ \mathrm{W} & \text { watt } \\ \% & \text { percentage } \\ { }^{\circ} \mathrm{C} & \text { degree Celsius }\end{array}$

\section{Greek symbols}

$$
\begin{array}{ll}
\mu \mathrm{L} & \text { microliter } \\
\mu \mathrm{m} & \text { micrometer }
\end{array}
$$

\section{INTRODUCTION}

The biodiesel is a renewable fuel, which is produced and used worldwide in large scale, mainly for being an excellent alternative to petroleum diesel (Chen et al., 2015). It is obtained by a transesterification process of vegetable oils or animal fats in the presence of alcohol using acidic or basic catalyst (Balat et al., 2010).

Currently, researches and investments are focused on looking for new biodiesel production technology employing other heating techniques such as microwave and ultrasound irradiation. Leadbeater and Stencel (2006) reported that by using microwaves irradiation, they achieved a methyl esters conversion rate of $98 \%$ using a molar ratio of 1: 6 (oil/alcohol) and $5 \%$ of $\mathrm{NaOH}$ or $\mathrm{KOH}$ catalyst.

The process of microwave irradiation accelerates the reactions, mostly because the energy is dissipated directly to the reaction components, resulting instantaneously high temperature. The transferred heat is more effective than the conventional heat, and the reaction can be completed in a much shorter time (Motasami and Ani, 2012). In addition, an experimental and theoretical study of molecular simulation performed by Asakuma et al. (2011) concluded that microwave irradiation promotes flat triglyceride molecules causing a reduction of the dipole moment and activation energy, increasing the vibration intensity of the carboxylic grouping. Thus, with the flat molecule, the space for alcohol attack the triglyceride molecule is amplified favoring the transesterification reaction. 
Besides the significant reduction in reaction times, the main advantages of using a microwave reaction synthesis are reduction of the undesired products; higher heating rates (extremely fast heating); energy saving; greater selectivity and efficiency and reduction in operating costs (Octavio and Miranda, 2011).

In addition, several studies highlight the development and production biodiesel using heterogeneous catalysts. The transesterification reaction for heterogeneous catalysts provides cleaner biofuels, which are more selective, that separate easily from the reaction mixture, reduce process steps and can be reused avoiding waste (Borges and Diaz, 2012). Literature studies show that the use of calcium oxide, magnesium oxide, strontium oxide, and mixed oxides are generally the most commonly studied (Borges and Diaz, 2012; Tariq et al., 2012). The calcium oxide is highlighted for being the most used oxide due to the $\mathrm{CaO}$ long life cycle, high catalytic activity, low solubility, especially with methanol, and requiring mild reaction conditions. Furthermore, the $\mathrm{CaO}$ can be easily found in various natural or industrial waste sources such as eggshells, and shellfish shells (Cho and Seo, 2010; Viriya-Empikul et al., 2010).

In recent years, some studies also reported biodiesel production using heterogeneous catalysis irradiation by microwave. Koberg et al., (2012) worked with strontium oxide ( $\mathrm{SrO})$ in the production of methyl esters with a power of $1100 \mathrm{~W}$ and they achieved $99.8 \%$ conversion in 10 seconds. Khemthong et al., (2012) investigated the production of biodiesel by microwave irradiation using calcium oxide from eggshells $(\mathrm{CaO})$. The results showed that with a molar ratio ethanol/oil 18:1, power of $900 \mathrm{~W}$, $15 \%$ of catalyst, and four minutes of reaction, a conversion rate of $96.7 \%$ was obtained.

In this study, the purpose is to evaluate the feasibility of an effective biodiesel production in microwave reactor employing the homogeneous and heterogeneous catalysis in order to optimize parameters such as reaction time, molar ratio alcohol/oil and catalyst percentage. In addition, it aimed to develop a heterogeneous catalysis based on wasted eggshells. According to Oliveira et al. (2009), eggshells wastes correspond to roughly 5.92 million tons per year of worldwide.

It is believed that the production of a renewable fuel with a cheap and effective production process that utilizes industrial waste is a huge step to remedy many problems of the contemporary society.

\section{EXPERIMENTS}

\section{Biodiesel production from microwave-assisted}

The production of biodiesel was performed by the transesterification reaction of the ABC soybean oil brand purchased at local shops in the city of Belo
Horizonte (Brazil). The alcohol used in all reactions was grade methanol $(100 \%$, Synth, Brazil). Two types of catalysts were used: a homogeneous and heterogeneous. Sodium methylate $(30 \%$ solution in methanol - $\mathrm{NaOCH}_{3}$, ISOFAR, Brazil) was used for the homogeneous catalyst and the heterogeneous catalyst was developed using wasted eggshells, which were acquired from local food markets.

All the reactions were carried out at microwave reactor (Start Synth - Milestone, Italy) in order to evaluate the prospects. The power and temperature were kept constant in every reaction being $800 \mathrm{~W}$ and $200^{\circ} \mathrm{C}$, respectively.

Each transesterification reaction forms fatty acid methyl esters (FAME) and glycerol. The product (FAMEs) and sub product (glycerol) separation was performed by decantation process using a separating funnel. The decantation time for each sample was 24 hours. Figures 1 and 2 show a decanted sample from a homogeneous and a heterogeneous catalysis reaction, respectively.

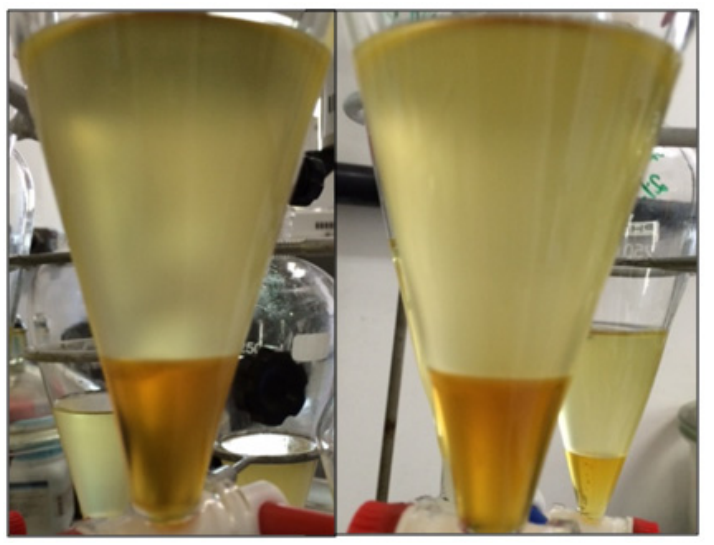

Figure 1. Biodiesel and glycerol produced in homogenous catalysis.

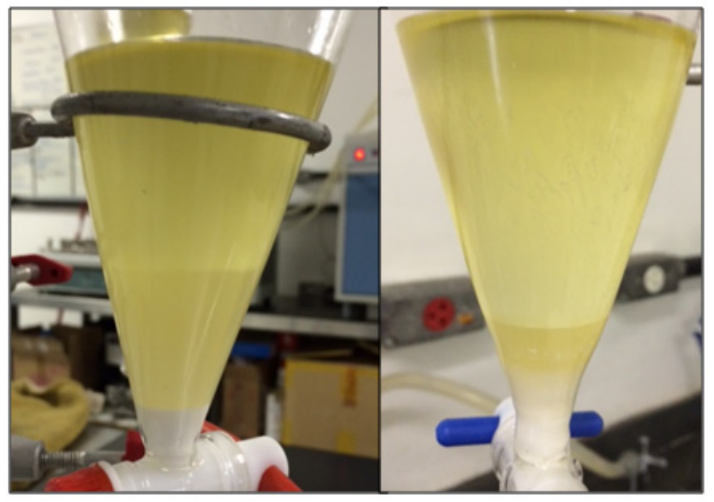

Figure 2. Biodiesel, glycerol and catalyst produced in heterogeneous catalysis.

After the biodiesel separation, a purification stage was necessary to remove eventual residue of glycerol and catalyst. A dry washing system was applied adding the Amberlite BD10DRY as 
adsorbent. The quantity of adsorbent added to the solution corresponded to $10 \%$ of the biodiesel (FAME) weight. The solution of biodiesel and adsorbent was shacked to orbital shaker at $200 \mathrm{rpm}$ for two hours. Subsequently, for eliminate the excess of alcohol, the biodiesel was submitted to a rotaryevaporation heated at approximately $120^{\circ} \mathrm{C}$.

The purified FAME were analyzed by gas chromatography, performed in accordance with EU norm EN 14103, using a GC-FID HP7820A apparatus (Agilent Technologies, USA) equipped with an auto-sampler (Agilent 7386B series) and data acquisition software EZChrom Elite Compact (Agilent Technologies, USA). Separations were accomplished at a constant hydrogen flow rate of 3 $\mathrm{mL}$ min-1 in a $15-\mathrm{m}$ long HP-INNOWAX capillary column ( $0.25 \mathrm{~mm}$ I.D. and $0.25 \mu \mathrm{m}$ film thicknesses). Samples $(1 \mu \mathrm{L})$ were injected in a split ratio of 1:50. Injector temperature was $250^{\circ} \mathrm{C}$ and the temperature program of the oven started with an initial temperature of $120^{\circ} \mathrm{C}$, followed by an increase in temperature up to $220^{\circ} \mathrm{C}$ at a rate of $7^{\circ} \mathrm{C} / \mathrm{min}$ for 12 minutes.

\section{Heterougenous catalyst prepartion and characterization}

The waste chicken white eggshells obtained to local market were washed with distilled water many times to remove impurities. Then, the eggshells were dried in a muffle for three hours at $80^{\circ}$ Celsius, followed by twelve hours at $100^{\circ}$ Celsius. In the biodiesel production reaction were tested pure calcined eggshells and KOH-doped eggshells. The $\mathrm{KOH}$-doped catalysts were prepared using wet impregnation method at concentrations of 10, 30 and $50 \%$ weight of $\mathrm{KOH}$ by weight of eggshell.

Afterwards, the dried eggshells were calcined at $1000^{\circ} \mathrm{C}$ in air atmosphere at a heating rate of $5^{\circ} \mathrm{C} / \mathrm{min}$ for $1 \mathrm{~h}$. In all cases, the final product was a fine white powder. Figure 3 showed the doped eggshells with $\mathrm{KOH}(50 \%)$ before and after calcination respectively.

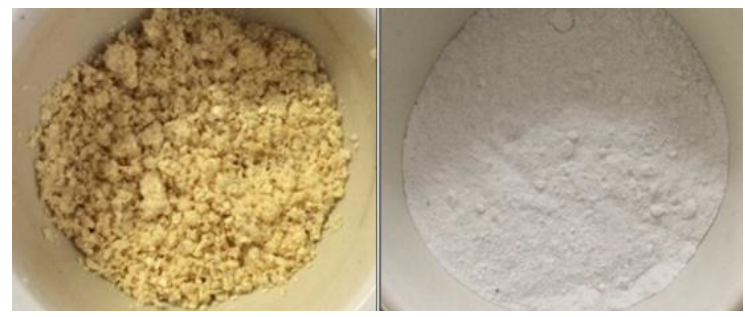

Figure 3. Heterogeneous doped catalyst with $50 \%$ of $\mathrm{KOH}$ before and after calcination, respectively.

PHILIPS X-Ray (XRD) diffractometer for powder samples (PANALYPTICAL) with the X'PertAPD system, PW3710/31 controller, 1830/40 PW generator, and PW 3020/00 goniometer was used to analyze heterogeneous catalysts. The thermogravimetric techniques also were employed to simulate the muffle effects with heating gradient was $5^{\circ} \mathrm{C}$ per minute until achieving $1000^{\circ} \mathrm{C}$, and the insufflation of synthetic air with a flow rate of $100 \mathrm{~mL}$ per minute.

\section{RESULTS AND DISCUSSION}

\section{Homogeneous and heterogeneous catalysis}

Given the results obtained with the gas chromatography, it was possible to quantify the grade of methyl esters formed and verify which parameters: molar ratio oil/alcohol, catalyst percentage and time, were great to the production of biodiesel in a microwave reactor using homogeneous and heterogeneous catalysis.

The results showed that the best conversion rate for homogenous catalysis was obtained with $3 \%$ of catalyst (sodium methylate) in 7 minutes of reaction, resulting in $99.1 \%$ methyl esters conversion (Fig. 4). Even in one minute of reaction the esters yield formed were $98.9 \%$, showing that noticed that the transesterification reaction by microwave irradiation is highly promising comparing to the conventional heat for the same reaction conditions (Fig. 5).

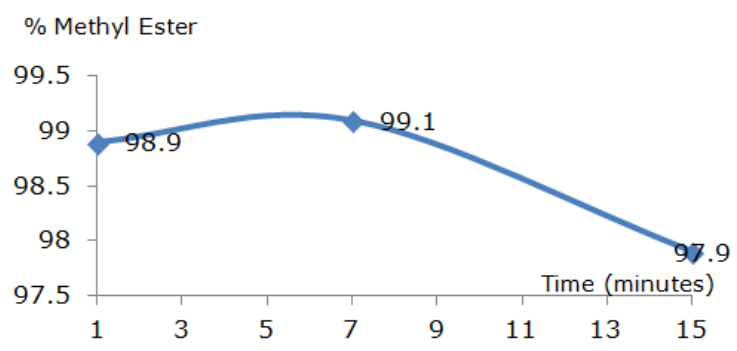

Figure 4. Time variation for homogeneous catalysis. Note: the reactions were performed with $3 \%$ of catalyst and molar ratio of 1:6 (oil/alcohol).

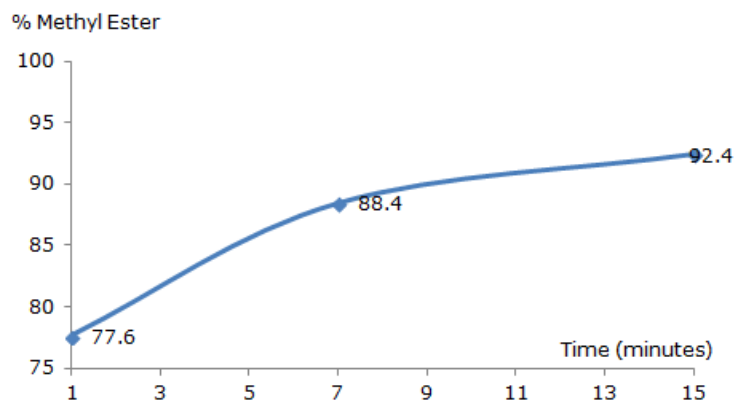

Figure 5. Time variation for conventional method.

Note: the reactions were performed with $3 \%$ of catalyst and molar ratio of 1:6 (oil/alcohol) at $60^{\circ} \mathrm{C}$.

For heterogeneous catalyst, the best results were acquired when the doped catalyst contained $50 \%$ of $\mathrm{KOH}$. Figure 6 shows that for fifteen minutes, the 3\% and $5 \%$ catalyst reaction achieved esters percentage 
of $97 \%$ and $100 \%$, respectively.

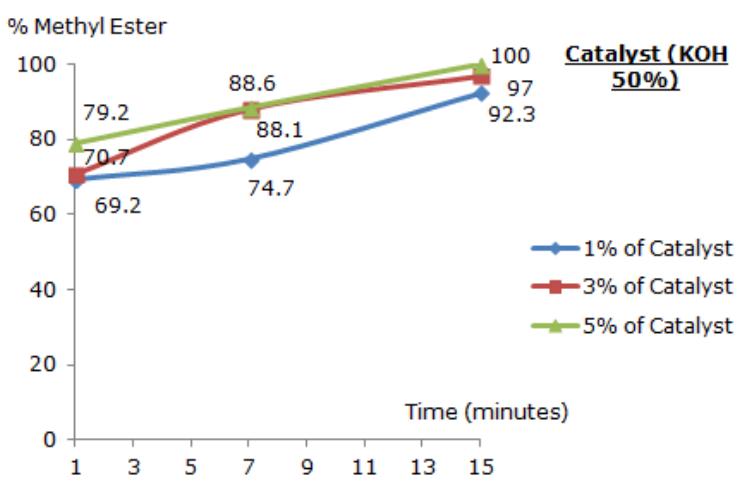

Figure 6. Transesterification reaction results with heterogeneous catalyst $(50 \% \mathrm{KOH})$

Note: all the heterogeneous reactions were performed with a molar ratio of 1:6 (oil/alcohol).

Figure 7 and 8 showed the results obtained with $10 \%$ and $30 \%$ of $\mathrm{KOH}$ doped catalyst varying time and catalyst percentage.

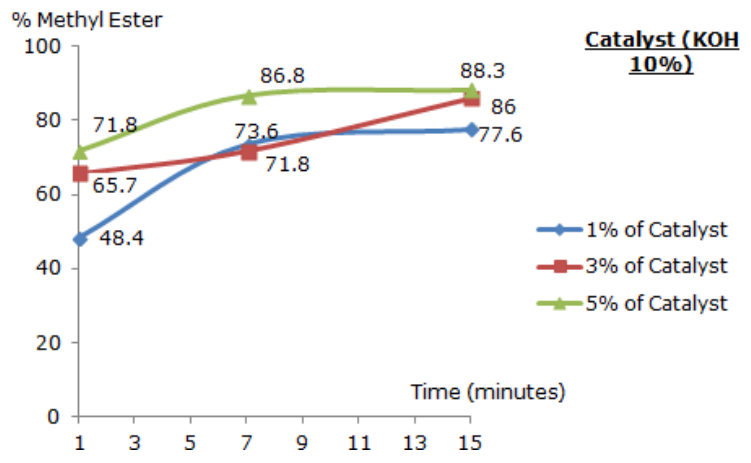

Figure 7. Transesterification reaction results with heterogeneous catalyst $(10 \% \mathrm{KOH})$.

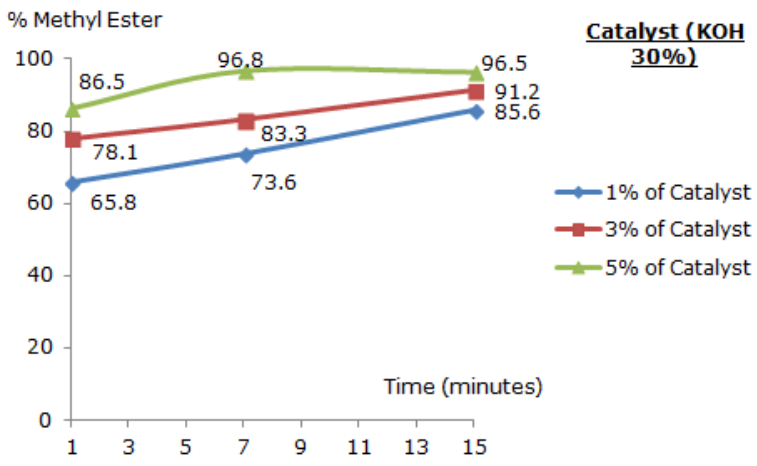

Figure 8. Transesterification reaction results with heterogeneous catalyst $(30 \% \mathrm{KOH})$.

Despite no result was under the National Agency of Petroleum, Natural Gas and Biofuels (ANP - Brazilian Institution) that determines the ester percentage minimum as $96.5 \%$, the results obtained can considered reasonable. The majority of studies on heterogeneous catalysis present reaction time and molar ratio higher than the ones chosen in this work. It appears that the longer the reaction and the higher the catalyst percentage, higher the reaction conversion is.

In Figure 8 can be noticed that when used $5 \%$ of $30 \% \mathrm{KOH}$ doped catalyst, the biodiesels produced in the reactions tested with 7 and 15 minutes already attend the specification of the Brazilian Standard, with formed methyl ester percentages of $96.8 \%$ and $96.5 \%$ respectively. This occurs, mainly, given the doped upgrade that increases the basic character of the catalyst, favoring the transesterification reaction.

The purity catalyst from eggshells (calcium oxide), which means, without $\mathrm{KOH}$ doping, reached only $31.2 \%$ of methyl ester in one minute of reaction, using 5\% of catalyst and 1:6 molar ratio. Even Cho et al. (2010) and Viriya-Empikul et al. (2010) have reported successful biodiesel production with calcium oxide derived from eggshells or shellfish shells, the application of non-doping alkaline catalyst did not achieve satisfying outcome when submitted to microwave irradiation.

Khemthong et al. (2012) reported to use pure calcium oxide in the transesterification reaction employing microwaves, but the applied conditions were extremely high, raising the process costs with a catalyst percentage $15 \%$ and the molar ratio oil/alcohol 1:18.

The $50 \% \mathrm{KOH}$ doped catalyst was recovered and reused in other reactions. Within 7 and 15 minutes reaction, with $5 \%$ of the recovered catalyst and 1:6 molar ratio resulted in a methyl ester conversion rate of $74.1 \%$ and $87.2 \%$, respectively. The catalytic performance of methyl ester formation decayed in $14.5 \%$ and $12.8 \%$ compared to the first reaction. It can inferred that this result is not ideal, but it is relatively satisfying.

\section{Characterization of heterogeneous catalyst}

The x-ray diffraction analysis provided the identification of the elements phases from the heterogeneous catalyst made by the eggshells. Figure 9 shows that after calcination the catalyst made by pure eggshells were predominantly calcium oxide $\mathrm{CaO}$ and a small part of hydrated calcium oxide (CaO.H2O), because of the absorption of humidity.

In the doped catalyst was observed calcium oxide formation $(\mathrm{CaO})$ and potassium ozonide $\left(\mathrm{KO}_{3}\right)$ in moderate quantities. It was also detected hydrated calcium oxide $\left(\mathrm{CaO} . \mathrm{H}_{2} \mathrm{O}\right)$, calcium carbonate $\left(\mathrm{CaCO}_{3}\right)$ and mixed calcium and potassium carbonate $\mathrm{K}_{2} \mathrm{Ca}\left(\mathrm{CO}_{3}\right)_{2}$. The presence of carbonates indicates that the samples were not totally calcined, even in small proportions (Fig. 10).

The 50\% KOH-doped catalyst was analyzed after use in the transesterification reactions and the $\mathrm{X}$-ray Diffraction analysis revealed its composition to undergo chemical reaction, with a complete disappearance of the potassium ozonide species and 
an increase in the amount of mixed calcium and potassium carbonates.

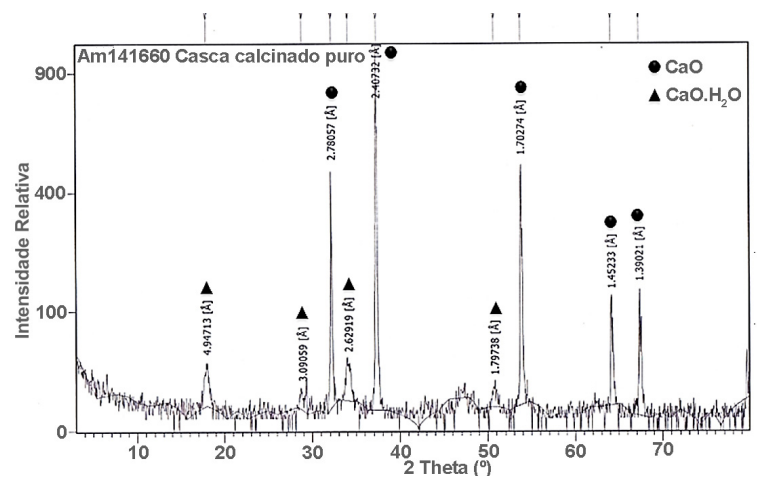

Figure 9. X-ray diffraction of the calcined pure eggshell.

It is important to highlight that diffraction spectrum noise observed were due to the lack of crystalline aspect of the samples analysed. According to NEVES (1998), the eggshell is considered a substantial amorphous material. When doping with $\mathrm{KOH}$, the noises increased significantly.

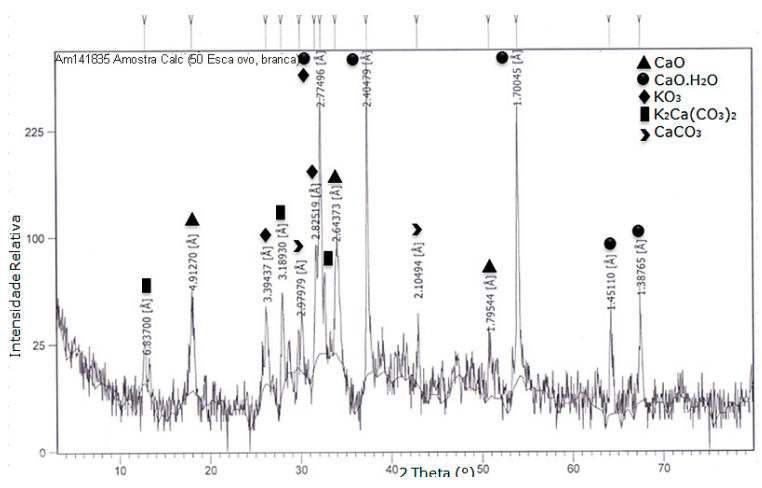

Figure 10. X-ray diffraction of the calcined 50\% $\mathrm{KOH}$ doped eggshell.

Through the thermogravimetric analysis, it was possible to keep up with the behaviour and mass changings of the sample in function of the temperature, in which could be visually observed where the sample transformations occurred.

Figure 11 shows that the $50 \% \mathrm{KOH}$ doped catalyst had a small mass loss between $50^{\circ}$ and $390^{\circ}$ Celsius, which can be attributed for a water and an organic matter loss. Between $390^{\circ}$ and $800^{\circ}$ Celsius, a significant mass loss can be related to $\mathrm{KOH}$ doping, since in the purity catalyst this aspect was not observed. Probably, because of the doping, intermediate chemical composts were produced, causing the decomposing process to initiate in lower temperatures.

Another mass loss can still be noticed between $800^{\circ}$ and $1000^{\circ} \mathrm{C}$, showing that a temperature increase would be necessary to provide a total decomposition of the sample (Fig. 11).

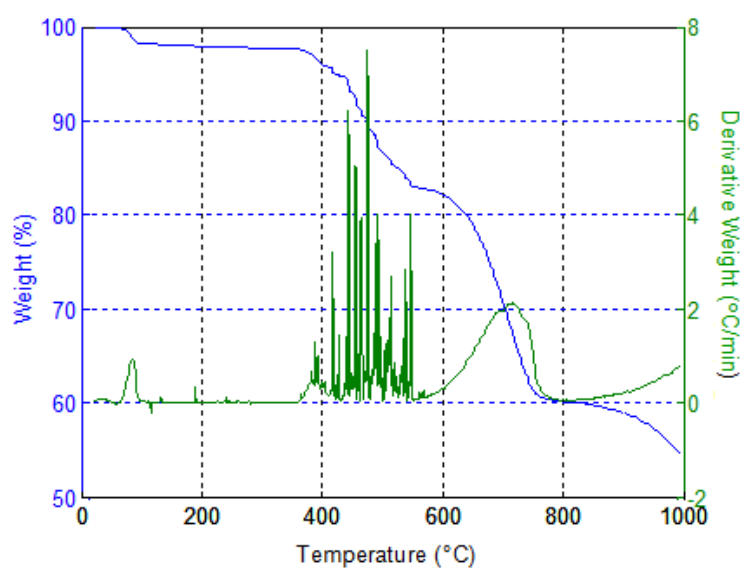

Figure 11. Thermal analysis of the $\mathrm{KOH}$ doped catalyst.

\section{CONCLUSIONS}

The biodiesel production in a microwave irradiation reactor is extremely promising to the biofuel industry. It was possible to obtained excellent yields of methyl esters applying both catalysis, homogenous and heterogeneous. The reaction time was significantly reduced compared to the conventional process. In only one minute of reaction, the methyl ester conversion obtained was $98.9 \%$ with the homogeneous catalyst and within 15 minutes, the heterogeneous catalysis accomplished 100\% using low molar ratios and moderate catalyst percentages.

In addition, the developed heterogeneous catalyst based on eggshells was compatible with the microwave reactor, especially when doped with potassium hydroxide. Despite the catalyst structure was not conserved intact after the transesterification reaction, the heterogeneous catalyst improved the biodiesel quality: make it easier to separate product and sub product produced, reduce purification steps, and have the possibility of being reused or regenerated that can be studying in future works.

\section{ACKNOWLEDGEMENTS}

Authors acknowledge financial support from CAPES, CNPq and FAPEMIG.

\section{REFERENCES}

Asakuma, Y., Ogawa, Y., Maeda, K., Fukui, K., and Kuramochi, H., 2011, Effects of Microwave Irradiation on Triglyceride Transesterification: Experimental and Theoretical Studies, Biochemical Engineering Journal, Vol. 58-59, pp. 20-24.

Balat, M., and Balat, H., 2010, Progress in Biodiesel Processing, Applied Energy, Vol. 87, No. 6, pp. 1815-1835.

Borges, M. E., and Díaz, L., 2012, Recent Developments on Heteregeneous Catalysts for Biodiesel Production by Oil Esterifiction and 
Transesterification Reactions: a Review, Renewable and Sustainable Energy Reviews, Vol. 16, No. 5, pp. 2839-2849.

Chen, G., Shan, R., Shi, J., Lui, C., and Yan, B., 2015, Biodiesel Production from Palm Oil using Active and Stable K Doped Hydroxyapatite Catalysts, Energy Conversion and Management, Vol. 98, pp. 463-469.

Cho, Y. B., and Seo, G., 2010, High Activity of Acid-Treated Quail Eggshell Catalyst in the Transesterification of Palm Oil with Methanol, Bioresource Technology, Vol. 101, pp. 8515-8519.

Khemthong, P., Luadthong, C., Nualpaeng, W., Changsuwan, P., Tongprem, P., Viriya-Empikul, N., and Faungnawakij, K., 2012, Industrial Eggshell Wastes as the Heterogeneous Catalysts for Microwave-Assisted Biodiesel Production, Catalys Today, Vol. 190, No. 1, pp. 112-116.

Koberg, M., Abu-Much, R., and Gedanken, A., 2011, Optimization of Biodiesel Production from Soybean and Wates of Cooked Oil: combining Dieletric Microwave Irradiation and SrO Catalyst, Bioresource Technology, Vol. 102, pp. 1073-1078, 2011.

Leadbeater, N. E., and Stencel, L. M., 2006, Fast, Easy Preparation of Biodiesel using Microwave Heating, Energy Fuels, Vol. 20, pp. 2081-2283.

Motasami, F., and Ani, F. N., 2012, A Review on Microwave-Assited Production of Biodiesel, Renew Sustain Energy Review, Vol. 16, pp. 47194733.

Neves, M. A., 1998, Alternativas para Valorização da Casca de Ovo como Complemento Alimentar e em Implantes Ósseos, Master Thesis, Departamento de Ciência e Tecnologia de Alimentos, UFSC, Florianópolis, SC. (in Portuguese)

Octavio, R. M. A. S., and Miranda, L. S. M., 2011, Microwave Assisted Organic Synthesis: a History of Success in Brazil, Química Nova, Vol. 34, No. 3, pp. 497-506.

Oliveira, D. A., Benelli, P., and Amante, E. R., 2009, Valorização de Resíduos Sólidos: casca de Ovos como Matéria-Prima no Desenvolvimento de Novos Produtos, in: 2nd Internacional Workshop Advances in Cleaner Production, Key Elements for a Sustainable World: Energy, Water and Climate Change, São Paulo. (in Portuguese)

Tariq, M., Ali, S., and Khalid, N., 2012, Activity of Homogeneous and Heterogeneous Catalysts, Spectroscopic and Chromatographic Characterization of Biodiesel: a Review, Renewable and Sustainable Energy Reviews, Vol. 16, pp. 63036316.

Viriya-Empikul, N., Krasae, P., Puttasawat, B., Yoosuk, B., Chollacoop, N., and Faungnawakij, K., 2010, Waste Shells of Mollusk and Egg as Biodiesel Production Catalyst, Bioresource Technology, Vol. 101, pp. 3765-3767. 